\title{
Campylobacter-like organisms and Candida in peptic ulcers and similar lesions of the upper gastrointestinal tract: a study of 247 cases
}

\author{
N K KALOGEROPOULOS, R WHITEHEAD \\ From the Department of Pathology, Flinders Medical Centre, Bedford Park, South Australia
}

SUMMARY Campylobacter-like organisms were detected by light microscopy in association with 57 of $102(56 \%)$ of gastric ulcers, all the gastric erosions associated with gastritis, three of five $(60 \%)$ of gastric erosions without gastritis, five of $13(39 \%)$ of mild superficial gastritis and two of $36(6 \%)$ of normal gastric mucosa. They were also seen in four of $20(20 \%)$ of duodenal ulcers, but not in duodenal erosions with duodenitis or normal duodenal biopsy specimens. They were seen in association with 12 of $64(19 \%)$ of cases of Barrett's oesophagus.

Moniliasis was seen in nine of $78(12 \%)$ of the gastric ulcers in which campylobacter-like organisms were found, and the incidence of moniliasis was three of $15(20 \%)$ in association with duodenal ulcers when ulcer debris was present in biopsy material, and in association with six of $25(24 \%)$ of cases of Barrett's oesophagus.

These findings do not support the hypothesis that campylobacter-like organisms cause inflammatory and ulcerative lesions of the upper gastrointestinal tract.

The presence of spiral or curved bacilli in close association with human gastric mucosa was described as early as $1896^{1}$ and noted subsequently on several occasions. $^{2-7}$ Recently Marshall and Warren cultured them and drew attention to their similarity to Campylobacter species. ${ }^{89}$ Subsequently they and others proposed that these organisms produce acute inflammation of the gastric mucosa and are causally related to peptic ulceration. This is plausible in cases of gastric ulcer and duodenal ulcer when other organisms are present. Doubt is raised, however, because they are not present in some gastric ulcers, and they are only seen in association with duodenal ulcers if antral type duodenal mucosa is seen ${ }^{10-12}$ even though they may be present in the antral mucosa. ${ }^{13}$

To investigate this possible association further we have correlated the presence of campylobacter-like organisms not only with peptic ulcer and associated inflammation of the stomach and duodenum, but also with erosion of stomach and duodenum with and without associated inflammation, inflammation (superficial gastritis) unassociated with ulceration, normal gastric and duodenal mucosa, and Barrett's oesophagus with and without peptic ulcer. We have also noted the presence or absence of Candida albicans

Accepted for publication 5 May 1988 in peptic ulcers of duodenum, stomach, and oesophagus. Candidiasis is generally regarded as an opportunistic infection in peptic ulcers, and it has no aetiological role. $^{14}$ is

\section{Material and methods}

Biopsy tissues were selected from our records of patients investigated for various gastrointestinal symptoms. They were classified according to the usually accepted histological criteria ${ }^{16}$ as being normal, or showing acute gastric erosion with or without gastritis, superficial gastritis, peptic ulcer associated with chronic gastritis, normal duodenal mucosa, duodenal erosion with duodenitis, and chronic duodenal ulcer. In cases of duodenal ulcer the presence of antral type mucosa was noted in all cases. Biopsy specimens from patients with Barrett's oesophagus with and without ulceration were also examined.

The investigation of these tissues for campylobacter-like organisms was undertaken in sections stained with haematoxylin and eosin and for Candida and other diseases by alcian blue and periodic acid Schiff after diastase digestion. Candida spores and pseudohyphae are easily recognised by their size and morphology in ordinary sections stained with haematoxylin and eosin and in all cases their positivity to 
periodic acid Schiff was shown. Campylobacter-like organisms as described by others were identified as haematoxyphilic curved or S shaped bacilli or both, ${ }^{810}$ depending on the plane of sectioning, ${ }^{17}$ in close association with the surface epithelium distributed in either continuous or focal arrangement. A strict definition of Barrett's oesophagus was used and cases were only included if their location was precisely noted at endoscopy and if the histological characteristics of partial intestinal change were present. A total of 269 biopsy specimens from 247 patients were examined. Sections stained with haematoxylin and eosin were screened at a magnification of 40 , and verification of suspected campylobacter like organisms was made using a magnification of 1000 under oil immersion. The following stains were used occasionally: Gram, modified Giemsa (without differentiation), ${ }^{18}$ Cresyl fast violet, ${ }^{19}$ and Warthin-Starry. ${ }^{8}$ The microscopic identification of campylobacter-like organisms in biopsy specimens correlates closely with their isolation on culture, ${ }^{131720-22}$ so as in most previous studies 310202324 we used this method of identification.

In the cases of peptic ulceration the presence of tissue or debris at the base of the ulcer was also noted. This was presumed to indicate that all the biopsy tissues originated in the edge of or in close proximity to the actual ulcer crater. If the accompanying inflammation was characterised by plasma cells and lymphocytes but no polymorphs it was designated chronic, but if polymorphs were present it was regarded as acute.

\section{Results}

The results are shown in tables 1 and 2. Campylobacter-like organisms were detected in $56 \%$ of gastric ulcers and there was no significant difference in the incidence between cases which included ulcer debris and those that did not. When there was no ulcer debris, however (table 2), $92 \%$ of those with acute inflammation contained campylobacter-like organisms, whereas in those with a chronic component of gastritis

Table 1 Incidence of campylobacter-like organisms and Candida albicans in various gastrointestinal lesions (269 biopsy specimens from 247 patients $)+\dagger$

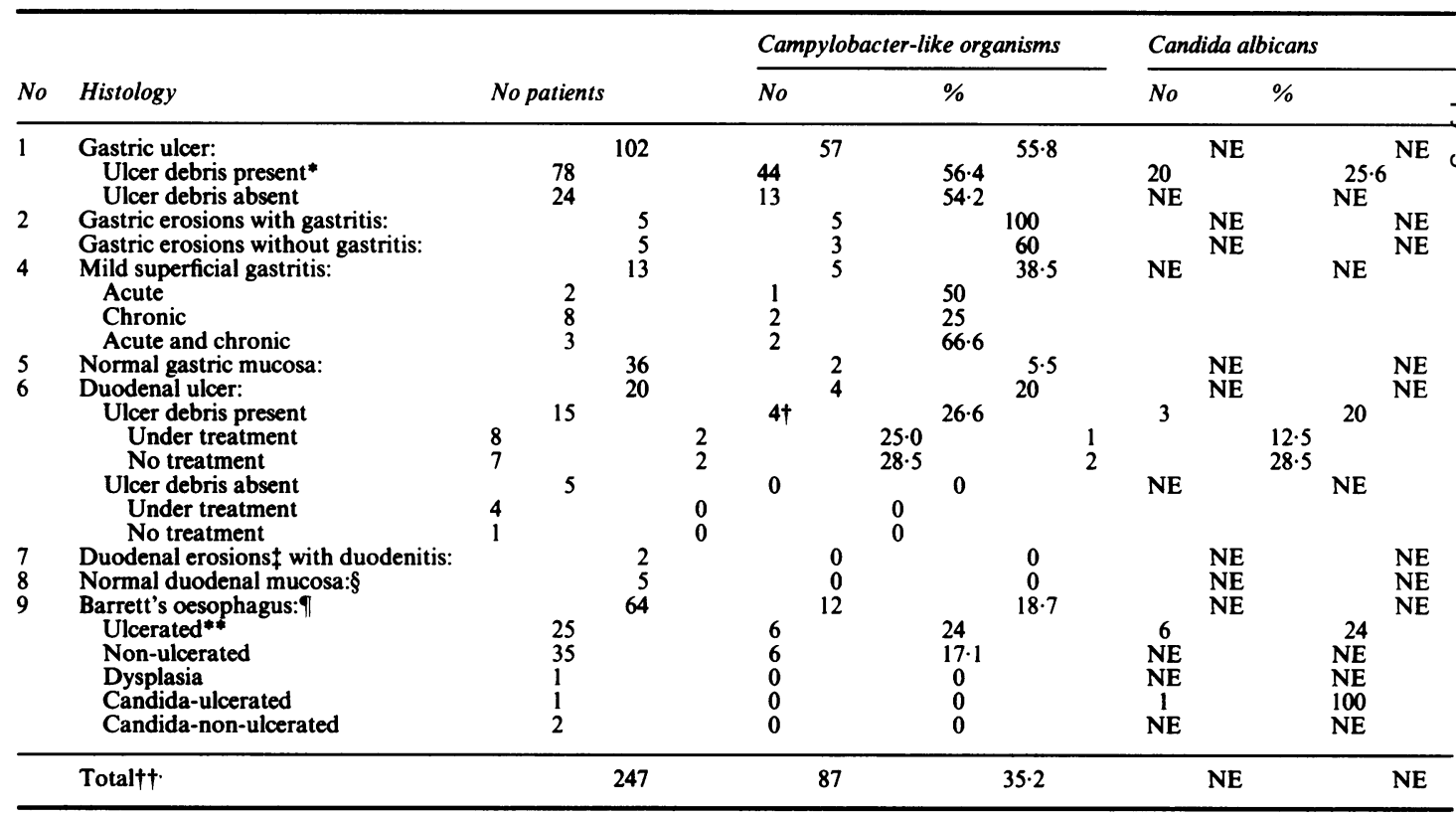

$\mathrm{NE}=$ not estimated.

††Two patients had three biopsies and another 14 patients had two biopsies.

* Coincidence of campylobacter-like organisms and Candida albicans was noticed in nine from $78(11.5 \%)$ cases.

†Three of the campylobacter-like organisms $(+)$ cases had also campylobacter-like organisms $(+)$ gastritis (the second biopsy specimen is not included in another group).

tOne of the cases is also included in gastric ulcer-campylobacter-like organisms ( +) group.

\$One patient is also included in the MSG-chronic campylobacter-like organisms $(-)$ group.

ףTwo patients are also included in gastric ulcer-campylobacter-like organisms $(+)$ group, one with campylobacter-like organisms $(+)$ and one with campylobacter-like organisms $(-)$ in oesophageal biopsy specimen.

** Coincidence of campylobacter-like organism and Candida albicans was noticed in one from 25 cases $(4 \%)$.

$+=$ positive; - = negative. 
Table 2 Incidence of campylobacter-like organisms in gastric ulcers present at endoscopy without ulcer debris in biopsy material

\begin{tabular}{lcl}
\hline Histological appearance & $\begin{array}{l}\text { No of } \\
\text { patients }\end{array}$ & $\begin{array}{l}\text { No (\%) with } \\
\text { campylobacter- } \\
\text { like organisms }\end{array}$ \\
\hline Healing ulcer & 6 & $1(17)$ \\
Ulcer margins with acute inflammation & 12 & $11(92)$ \\
Ulcer margins with chronic inflammation & 6 & $1(17)$ \\
\hline Total & 24 & $13(54)$ \\
\hline
\end{tabular}

only $17 \%$ showed campylobacter-like organisms. The incidence of the organisms in gastric erosions with and without associated gastritis was $100 \%$ and $60 \%$, respectively. Campylobacter-like organisms were also detected in five of $13(39 \%)$ with associated mild superficial gastritis but no ulcer, and in only two of 36 $(6 \%)$ of samples of normal gastric mucosa.

Campylobacter-like organisms were not seen in the biopsy specimens of normal duodenal mucosa, nor were they seen in either of the two erosions associated with duodenitis. Campylobacter-like organisms were detected in four of $20(20 \%)$ duodenal ulcers, and in three of these campylobacter-like organisms were also seen in gastric biopsy specimens taken at the same examinations in which there was a mild superficial gastritis in one case, and atrophic gastritis in two. One patient with a duodenal erosion without camplyobacter-like organisms and two patients with duodenal ulcers without campylobacter-like organisms had campylobacter-like organisms in the gastric mucosa. Campylobacter-like organisms were only seen in tissue from duodenal ulcers in association with foci of antral type epithelium.

Of the 64 cases of Barrett's oesophagus (19\%) were associated with campylobacter-like organisms but it was noticeable that in the presence of ulceration the percentage rose to $24 \%$.

Candidiasis was present in 20 of $78(26 \%)$ gastric ulcers if ulcer debris was present, and if only gastrectomy specimens are considered the incidence was $38 \%$. In nine cases of ulcers positive for Candida (12\%) campylobacter-like organisms were also detected. In duodenal ulcers candidiasis occurred in $20 \%$ without accompanying campylobacter-like organisms. In cases in which there was ulcer debris in the biopsy material, the incidence of campylobacter-like organisms was almost equal to that of Candida. Interestingly, in one case with both duodenal ulcer and Barrett's ulcer only the duodenal ulcer contained Candida. Candida was, however, also seen in six of the 25 cases of ulcerated Barrett's oesophagus (24\%). There was a similar incidence of campylobacter-like organisms, but campylobacter-like organisms and Candida were seen together in only one case.

\section{Discussion}

"Can these spirochaetes, which exist in man, and in animals commonly employed for experiments and which are ordinarily harmless, be ignored in physiologic and pathologic studies on the stomach?" This question posed by Doenges ${ }^{3}$ was addressed 50 years later by Marshall and Warren, ${ }^{9}$ who stated that campylobacter-like organisms are "aetiologically related to chronic antral gastritis and, probably, to peptic ulceration also".

Since that time it has been claimed in support of this statement that campylobacter-like organisms occur in the antrum in almost all patients with duodenal ulcers and in up to $90 \%$ of those with non-autoimmune gastritis. ${ }^{95}$ In comparison campylobacter-like organisms are found in only 3.4 to $24 \%$ of normal subjects ${ }^{913}$ and in about $21 \%$ of patients with type A gastritis. ${ }^{26}$ Antibodies to campylobacter-like organisms can be detected in serum samples ${ }^{202728}$ and gastric juice ${ }^{18}$ of patients who harbour the organism, and after ingestion of campylobacter-like organisms it is claimed that a gastritis can be induced in previously normal volunteers. $^{29}$ The organism is sensitive to antimicrobials including metronidazole,,$^{30} 31$ and it has been claimed that metronidazole heals peptic ulcers ${ }^{32}$; bismuth compounds are also effective. ${ }^{33-36}$ It is also said that colonisation by campylobacter-like organisms persists in patients treated with $\mathrm{H}_{2}$ receptor antagonists, the use of which is known to be associated with a higher incidence of relapse of ulcers than other agents. ${ }^{37}$

There is, however, evidence that campylobacter-like organisms do not have a causal role in peptic ulcer disease. They are not present in all lesions, and there is a better association with a history of ulcer $(53 \%)$ than with active ulceration $(46 \%){ }^{25}$ The correlation with the acute inflammatory activity of gastritis has been disputed ${ }^{1720}$ and campylobacter-like organisms persist despite the healing of the ulcer. ${ }^{17213839}$ They are sometimes present even when the mucosa is histologically normal ${ }^{1340}$ and they occur in about $24 \%$ of asymptomatic healthy volunteers with histological evidence of gastritis. ${ }^{22}$ Gastric ulcers from which campylobacter-like organisms are found have similar clinical courses to those in which they are not found, ${ }^{41}$ and in a study from Hong Kong ${ }^{39} 51 \%$ of duodenal ulcers healed after placebo treatment despite the persistence of campylobacter-like organisms in the antrum. Finally in a study of duodenal biopsy specimens there was no correlation between the presence of campylobacter-like organisms and active inflammation. ${ }^{23}$

The previously claimed association between the presence of campylobacter-like organisms and gastric ulcer has varied between $35 \%{ }^{40}$ and $80 \%,{ }^{79}$ but other 
investigators ${ }^{131721}$ report an incidence similar to that in the present study $(56 \%)$. The presence of ulcer debris does not influence the result, but in its absence an acute inflammatory component was associated with campylobacter-like organisms in $92 \%$ of cases compared with $17 \%$ when the inflammation was chronic. This is similar to some previous reports ${ }^{933942}$ but not all. ${ }^{17} 20$

Gastric erosions (particularly those not associated with gastritis - for example, in aspirin abusers) have hitherto received scant attention, though about $7 \%$ are said to contain campylobacter-like organisms. ${ }^{25}$ In this study all the gastric erosions associated with gastritis showed campylobacter-like organisms, which were also present in $60 \%$ of those without gastritis. This clearly weakens the argument that campylobacter-like organisms are the only cause of gastric ulceration, but would favour the theory that gastric erosions (especially if accompanied by inflammation) form a suitable milieu for colonisation by campylobacter-like organisms.

In mucosa showing mild superficial gastritis $38 \%$ of specimens showed campylobacter-like organisms and there was a good correlation with acute inflammation. Though the numbers are small, it is an unusual lesion to find alone in routine upper gastrointestinal biopsy material. Our findings contrast with those of Jones $e t$ $a l^{20}$ and Andersen $e t a l,,^{23}$ however, who found that $83 \%$ of superficial gastritis specimens contained campylobacter-like organisms. In the first of these studies there was no association with the type of inflammation, and in the second there was no grading of the superficial gastritis. If cases of mild chronic superficial gastritis are excluded from our study the incidence of campylobacter-like organisms in mild superficial gastritis with an acute component rises to $60 \%$.

Our results from normal gastric mucosa $(6 \%)$ seem to be similar to those of Marshall and Warren ${ }^{9}(6 \%)$, Andersen et al ${ }^{23}(5 \%)$ and Taylor et al ${ }^{24}(5 \%)$, but cases of mild superficial gastritis are often included in this category. This could account for the higher incidences of 9-14\% campylobacter-like organisms in normal mucosa reported by others. ${ }^{101340}$ If the mild superficial gastritis and normal mucosal biopsy specimens in our study are considered together, the incidence of campylobacter-like organisms rises to $15 \%$. Though numbers are comparatively small, campylobacter-like organisms are not usually found in specimens from normal mucosa. Jones et $a l^{20}$ for example, were unable to find campylobacter-like organisms in 15 cases, but found one patient with a positive culture and circulating serum antibodies (7\%), and McNulty and Watson ${ }^{21}$ could not find campylobacter-like organisms in 21 cases. In duodenal ulcers, campylobacter-like organisms occurred in $20 \%$ of all cases, but their presence correlated with the coexistence of ulcer debris. This is in keeping with the fact that accompanying mucosa was likely to have been taken from the acutely inflamed ulcer margin and is indicative of the association between campylobacter-like organisms and intraepithelial infiltration of polymorphonuclear leucocytes. ${ }^{42}$ In biopsy specimens of duodenal ulcers that are accompanied by ulcer debris therefore, campylobacter-like organisms were seen in $27 \%$.

Infiltration by polymorphonuclear leucocytes is generally extensive $e^{41}$ and this is in keeping with the observation that campylobacter-like organisms were present in equal numbers in the two subgroups of gastric biopsy specimens (table 1). The reported incidence of campylobacter-like organisms in biopsy specimens from the duodenal cap show pronounced variations. Some workers claim that they are absent ${ }^{13}$ despite campylobacter-like organisms being present in the antral biopsy specimens (as was the case in two of three patients in our study) but others claim that they are present in up to $85 \%$ of cases. ${ }^{10-12}$ In this series their presence varied between 0 and $30 \%$ depending on the presence of ulcer debris, acute inflammation, and previous treatment (table 1). In most other studies of duodenal ulcers, only gastric mucosal biopsy specimens were examined and this adds to the confusion. ${ }^{917212239}$ As reported by others, however, ${ }^{101213}$ normal duodenal mucosa was not associated with the presence of campylobacter-like organisms. We wereo also unable to see campylobacter-like organisms in: biopsy specimens from the duodenal caps of patients with duodenal erosions with duodenitis, an entity not considered in previous studies.

Barrett's oesophagus has not previously been studied for the presence of campylobacter-like organisms, which were present in $19 \%$ of 64 cases. If ulceration was present, they were slightly more frequent $(24 \%)$ compared with $17 \%$ in non-ulcerated cases, but this is not significant. The presence of campylobacter-like organisms in Barrett's oesophagus with or without ulceration (as in peptic ulceration elsewhere) obviously introduces the possibility that they have an aetiological importance. In view of the established place of gastric reflux in the acquisition of Barrett's epithelium, the part played by campylobacter-like organisms in the ulcerative process itself must be considered, but our results do not support this and it seems much more likely that the campylobacter like organisms are commensals.

Although the overall incidence of Candida in gastric ulcers was $26 \%$ (which is higher than that found by Scott and Jenkins $(16 \%)^{15}$ and lower than that reported by Katzenstein and Maksem $(33 \%)^{14}$ and GotliebJensen and Andersen $(36 \%)^{43}$ ) if only gastrectomy specimens were considered the incidence was $38 \%$, 
which is similar to the $33 \%$ found by Katzenstein and Maksem, ${ }^{14}$ who also examined only gastrectomy specimens.

This study is unique in that we know of no previous data about the coexistence of campylobacter-like organisms and Candida in upper gastrointestinal biopsy tissue. In gastric ulcers both organisms were seen in $12 \%$ of biopsy specimens. In duodenal ulcers with ulcer debris in the biopsy material, Candida and campylobacter-like organisms were seen with almost equal regularity. Similarly, in Barrett's oesophagus with ulcers Candida was seen in $24 \%$ (an incidence similar to campylobacter-like organisms), but they occurred together in only one case. These findings probably indicate that the organisms prefer different environmental conditions for colonisation and growth. If some forms of peptic ulcer are caused by campylobacter-like organisms, however, then the same argument could apply to Candida, but against this is the finding of Candida in a duodenal ulcer when a coexistent Barrett's oesophageal ulcer was not affected. Candida is found only in association with necrotic ulcer debris and not neighbouring mucosa, and both organisms-which are probably ubiquitous - may colonise the upper gastrointestinal tract and multiply under the right circumstances.

In conclusion, our findings - particularly in erosions without inflammation, mild superficial gastritis, and Barrett's oesophagus-and the equal incidence of campylobacter-like organisms and Candida in ulcerated Barrett's oesophagus and duodenal ulcers, do not support the argument that campylobacter-like organisms cause gastritis and peptic ulceration. Indeed, it is more logical to propose that the presence of these lesions in some way promotes colonisation by these organisms.

\section{References}

1 Salomon H. Centralbl f. Bakt (Abt 1) 1896;19:433. Quoted by: Doenges L. Spirochetes in the gastric glands of Macacus rhesus and of man without related disease. Archives of Pathology 1939;27:469-77.

2 Krienitz W. Ueber das auftreten von mageninhalt bei carcinoma ventriculi. Dtsch Med Wochenschr 1906;22:872. 'Quoted by Doenges $L$. Spirochetes in the gastric glands of Macacus rhesus and of man without related disease. Archives of Pathology 1939;27:469-77.

3 Doenges JL. Spirochetes in the gastric glands of Macacus rhesus and of man without related disease. Archives of Pathology 1939;27:469-77.

4 Freedburg AS, Barron LE. The presence of spirochaetes in human gastric mucosa. Am J Dig Dis 1940;7:443-5.

5 Ito $S$. Anatomic structure of the gastric mucosa. In: Heidel US, Cody CF, eds. Handbook of physiology, section 6: alimentary canal, volume II; secretion. Washington DC: American Physiological Society, 1967:705-41.

6 Fung WP, Papadimitriou JM, Matz LR. Endoscopic, histological and ultrastructural correlations in chronic gastritis. Am J Gastroenterol 1979;71:269-79.
7 Steer HW, Colin-Jones DG. Mucosal changes in gastric ulceration and their response to carbenoxolone sodium. Gut 1975;16: 590-7.

8 Warren JR, Marshall BJ. Unidentified bacilli on gastric epithelium in active chronic gastritis. Lancet 1983;i:1273-5.

9 Marshall BJ, Warren JR. Unidentified curved bacilli in the stomach of patients with gastritis and peptic ulceration. Lancet 1984;:1311-5.

10 Johnston BJ, Reed PI, Ali MH. Campylobacter like organisms in duodenal and antral endoscopic biopsies: relationship to inflammation. Gut 1986;27:1132-7.

11 Phillips AD, Hine KR, Holmes GKT, Woodings DF. Gastric spiral bacteria. Lancet 1984;ii:100-1.

12 Steer HW. Surface morphology of the gastroduodenal mucosa in duodenal ulceration. Gut 1984;25:1203-10.

13 Burnett RA, Forrest JAH, Girdwood RWA, Fricker CR. Campylobacter like organisms in the stomachs of patients and healthy individuals. Lancet 1984;i:1349.

14 Katzenstein A-LA, Maksem J. Candidal infection of gastric ulcers: histology, incidence and clinical significance. Am J Clin Pathol 1979;71:137-41.

15 Scott BB, Jenkins D. Gastro-oesophageal candidiasis. Gut 1982;23:137-9.

16 Whitehead R. Mucosal biopsy of the gastrointestinal tract. 3rd ed. Philadelphia: WB Saunders, 1985.

17 Price AB, Levi J, Dolby JM, et al. Campylobacter pyloridis in peptic ulcer disease: microbiology, pathology and scanning electron microscopy. Gut 1985;26:1183-8.

18 Rathbone BJ, Wyatt JI, Heatley RV. Campylobacter pyloridis-a new factor in peptic ulcer disease? Gut 1986;27:635-41.

19 Burnett RA, Brown IL, Findlay J. Cresyl fast violet staining method for campylobacter like organisms. J Clin Pathol 1987;40:353.

20 Jones DM, Lessells AM, Eldridge J. Campylobacter like organisms on the gastric mucosa: culture, histology and serological studies. J Clin Pathol 1984;37:1002-6.

21 McNulty CAM, Watson DM. Spiral bacteria of the gastric antrum. Lancet 1984;i:1068-9.

22 Langenberg ML, Tytgat GNJ, Schipper MEI, Rietra PJGM, Zanen HC. Campylobacter like organisms in the stomach of patients and healthy individuals. Lancet 1984;i:1348.

23 Andersen LP, Holck S, Poulsen CO, Elsborg L, Justesen T. Campylobacter pyloridis in peptic ulcer disease. I. Gastric and duodenal infection caused by C. pyloridis: histopathologic and microbiologic findings. Scand J Gastroenterol 1987;22:219-24.

24 Taylor DE, Hargreaves JA, Ng LK, Sherbaniuk RW, Jewell LD. Isolation and characterization of Campylobacter pyloridis from gastric biopsies. Am J Clin Pathol 1987;87:49-54.

25 Ireland A, Holdstock G, Booth L, Hawtin P, Bamforth J, Pearson A. Clinical correlates of spiral shaped organisms from antral biopsies. Gut 1984;25:A1136.

26 O'Connor HJ, Axon ATR, Dixon MF. Campylobacter-like organisms unusual in type A (pernicious anaemia) gastritis. Lancet 1984;ii: 1091.

27 Marshall BJ, McGechie DB, Francis GJ, Utley PJ. Pyloric campylobacter serology. Lancet 1984;ii:281.

28 Kaldor J, Tee W, McCarthy P, Watson J, Dwyer B. Immune response to Campylobacter pyloridis in patients with peptic ulceration. Lancet 1985;i:921.

29 Marshall BJ, Armstrong JA, McGechie DB, Glancy RJ. Attempt to fulfil Koch's postulates for pyloric Campylobacter. Med J Aust 1985;142:436-9.

30 Marshall BJ, McGechie DB, Rogers PA, Glancy RJ. Pyloric Campylobacter infection and gastroduodenal disease. Med $J$ Aust 1985;142:439-44.

31 Lambert JR, Hansky J, Davidson A, Pinkard K, Stockman K. Campylobacter like organisms (CLO)-in vivo and in vitro susceptibility to antimicrobial and antiulcer therapy. Gastroenterology 1985;88:1462.

32 Shirokova KI, Filomonov RM, Poliakora LV. Metronidazole in 
the treatment of peptic ulcer. Klin Med (Mosk) 1981;59:48-50.

33 Martin DF, May SJ, Tweedle DEF, Hollanders D, Ravenscrof MM, Miller JP. Difference in relapse rates of duodenal ulcer after healing with cimetidine or tripotassium dicitrato bismuthate. Lancet $1981 ; \mathbf{i}: 7-10$.

34 Jones DM, Eldridge J, Whorwell PJ, Miller JP. The effects of various anti-ulcer regimens and antibiotics on the presence of Campylobacter pylorides and its antibody. In: Pearson AD, Skirrow MB, Lior H, eds. Campylobacter III. Proceedings of the Third International Workshop on Campylobacter Infections. London: Public Health Laboratory Service, 1985.

35 Langenberg ML, Rauws EAJ, Schipper MEI, et al. The pathogenic role of Campylobacter pyloridis studied by attempts to eliminate these organisms. In: Pearson AD, Skirrow MB, Lior H, eds. Campylobacter III. Proceedings of the Third International Workshop on Campylobacter Infections. London: Public Health Laboratory Service, 1985.

36 McNulty CAM, Davis M, Donovan IA, Melikian V, Wise R. A trial to compare treatment with Pepto-Bismol (bismuth subsalicylate), placebo and erythromycin for the eradication of Campylobacter pyloridis with gastritis. In: Pearson AD, Skirrow MB, Lior H, eds. Campylobacter III. Proceedings of the Third International Workshop on Campylobacter Infections. London: Public Health Laboratory Service, 1985.
37 McLean AJ, Harrison PM, Ionnides-Demos LL, Byrne AJ, McCarthy P, Dudley FJ. Microbes, peptic ulcer, and relapse rates with different drugs. Lancet 1984;if:525-6.

38 Thomas JM, Poynter D, Cooding C, et al.Gastric spiral bacteria. Lancet 1984;ii: 100.

39 Eo J, Lui I, Hui WM, Ng MMT, Loam SK. A study on the correlation of duodenal ulcer healing with campylobacter-like organisms. J Gastroenterol Hepatol 1986;1:69-74.

40 Rollason TP, Stone J, Rhodes JM. Spiral organisms in endoscopic biopsies of the human stomach. J Clin Pathol 1984;37:23-6.

41 Pym BM, Eckstein RP, Piper DW, Stiel D. Campylobacter-like organisms and gastric ulcer. Med J Aust 1986;144:387-8.

42 Steer HW. The gastro-duodenal epithelium in peptic ulceration. $J$ Pathol 1985;146:355-62.

43 Gotlieb-Jensen K, Andersen J. Occurrence of Candida in gastric ulcers: significance for the healing process. Gastroenterol 1983;85:535-7.

Requests for reprints to: Professor R Whitehead, Department of Pathology, Flinders Medical Centre and Flinders University of South Australia, Bedford Park, South Australia 5042. 